\title{
The Importance of Three-Dimensional Imaging from CBCT in Elucidating a Well-Defined Radiolucency Image within the Maxillary Sinus: A Case Report
}

\author{
Ricardo Alves de Mesquita, Cláudia Borges Brasileiro, Tânia Mara Pimenta Amaral \\ Department of Oral Surgery and Pathology, School of Dentistry, Universidade Federal de Minas Gerais, Belo \\ Horizonte, Brazil \\ Email: ramesquita@ufmg.br
}

Received 25 June 2014; revised 20 July 2014; accepted 10 August 2014

Copyright $@ 2014$ by authors and Scientific Research Publishing Inc.

This work is licensed under the Creative Commons Attribution International License (CC BY).

http://creativecommons.org/licenses/by/4.0/

\section{(c) (i) Open Access}

\begin{abstract}
This study describes a case of antral septum with alveolar process extension that is identified using cone-beam computed tomography (CBCT). Periapical radiolucency was observed in the maxillary sinus, and clinical and radiographic examinations ruled out the possibility of odontogenic lesions. CBCT was performed to elucidate the radiolucency identified using periapical radiography. A 3-D image indicated that the maxillary sinus extended into the alveolar process toward the palatal cortical bone in the region of the maxillary right first molar, as well as an antral septum extending from the inferior and lateral wall of the right maxillary sinus. CBCT is an important tool for use in dental practice because CBCT images reveal the entire volume of the maxillary sinus and allow for identification of patient anatomy and anatomical variations, which is essential for planning appropriate surgical interventions.
\end{abstract}

\section{Keywords}

Diagnostic Imaging, Cone-Beam Computed Tomography, Radiography, Maxillary Sinus

\section{Case Report}

The paranasal sinuses begin to develop during the fetal period, in the third week of gestation, as invagination of the nasal mucosa into the lateral nasal wall, maxillae, frontal, ethmoid and sphenoid bones [1]-[3]. The maxillary sinus is the first sinus to develop; at birth, it is filled with fluid and becomes pneumatized [4]. The maxillary 
sinus can present anatomical variations such as pneumatization, antral septa, hypoplasia and exostosis [5].

Pneumatization is the development of pneumatic cavities in bone [6], and in the case of the maxillary sinus is characterized by sinus palatine extension inferomedially into the hard palate toward the midline, lateral extension into the zygomatic bone, sinus recess to the alveolar ridge and infraorbital recess, and anterior projection along the roof of the maxillary sinus [7]. Posterior extension into the tuberosity can also be observed [5].

Septa were first described by Underwood in 1910 [8], who published a detailed description of maxillary sinus anatomy and described septa as walls of cortical bone within the maxillary sinus emerging from the floor and lateral wall like an inverted gothic arch [9]. In this presentation, the three-dimensional image provided by CBCT was fundamental to identifying the source of the radiolucency and to evaluating the extension of the antral septum and alveolar process.

A 24-year-old male patient at the School of Dentistry, Universidade Federal de Minas Gerais, presented with pain during mastication in the region of the right maxillary second premolar. He reported that the symptoms began three months prior but did not experience a gradual increase in intensity. Clinical examination revealed the presence of composite resin restoration. Periapical radiograph indicated restoration integrity and mild thickening of the periodontal ligament space in the root apex, which suggested pericementitis. No recurrent dental caries was observed. The periapical radiograph also revealed a well-defined unilocular radiolucency image inside the right maxillary sinus unrelated to the sinus wall or upper right posterior teeth roots (Figure 1). This radiolucent image that seemed to us within the maxillary sinus was not conclusive for any diagnosis. There was no history of previous maxillary sinus infection.

Conventional images have some limitations. They provide two-dimensional view of three-dimensional anatomy with superimposition of dentoalveolar structures. Furthermore, geometric distortion of these structures is often observed. TC scan obtained much more crisp and sharp details than conventional radiographs. So, CBCT was performed to provide more specific details about the radiolucency image. CBCT was performed using the KODAK 9000C 3D (Kodak Dental Systems, Carestream Health, USA), with a small field of view $(5 \times 3.7 \mathrm{~mm})$, tube voltage of $70 \mathrm{kV}$, tube current of $107 \mathrm{mAs}$ and exposure time of 40 seconds. Once volumetric data were acquired, images were converted into the DICOM (Digital Imaging and Communication in Medicine) file format and evaluated using Imaging Studio software (Anne Solutions, Brazil). Multiplanar reconstruction (MPR) or images in three planes (axial, sagittal and coronal) and cross sectional images were used for case evaluation.

The axial, sagittal and coronal planes revealed the presence of maxillary sinus extension into the alveolar process toward the palatal cortical bone near the maxillary right first molar. Additionally, the antral septum extended from the inferior and lateral wall of the right maxillary sinus (Figure 2), which ruled out any possibility of cystic lesions in the maxillary sinus. The patient was given the diagnosis of an antral septum with extension of the maxillary sinus into the alveolar process. The different planes of images and knowledge of sectional anatomy were essential to make the diagnosis.

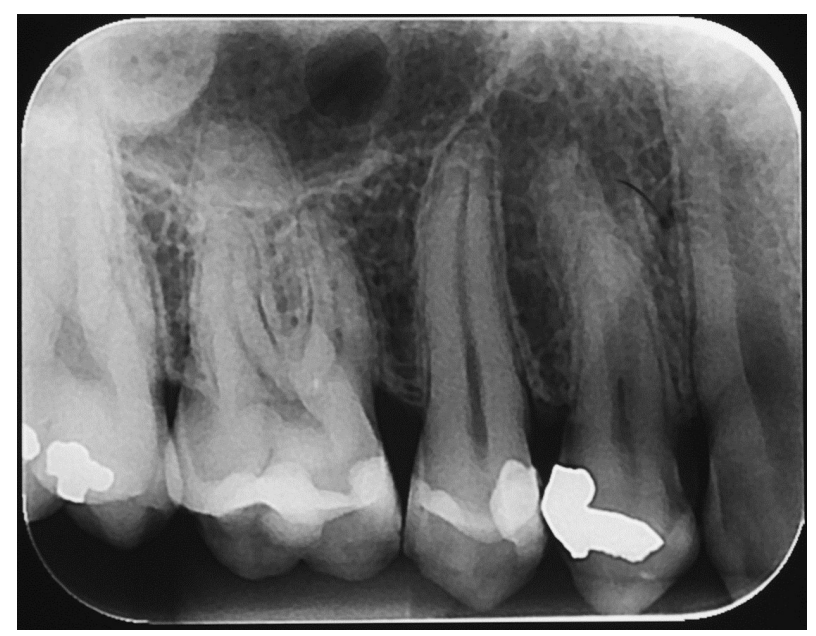

Figure 1. Periapical radiography. Note a radiolucent, unilocular, well-defined, overlapping the maxillary sinus, with no relation to upper right posterior teeth (16 and 15). 


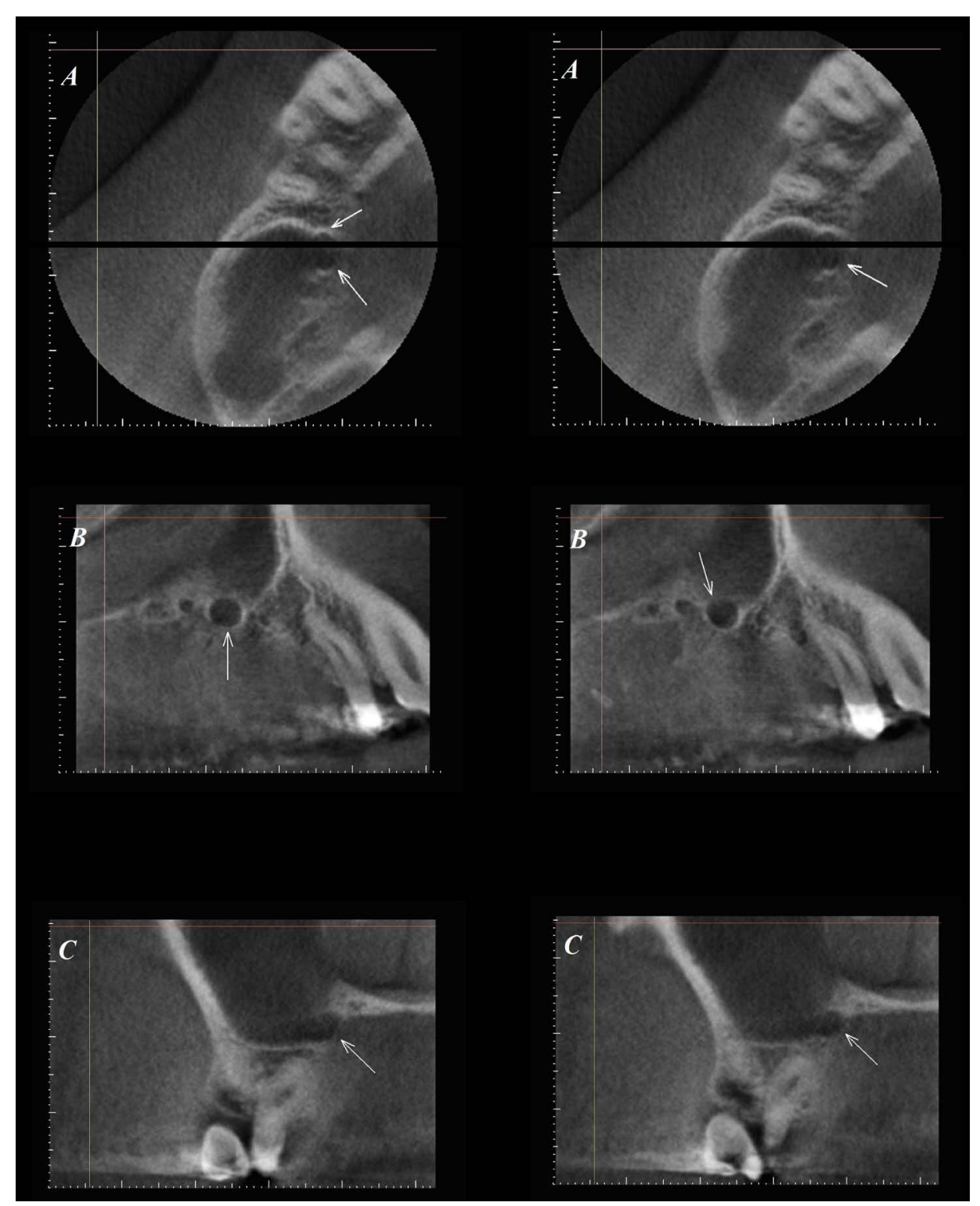

Figure 2. Axial CBCT (A), Sagittal CBCT (B), Coronal CBCT (C). CBCT scans show maxillary sinus extending into the palatine process of the maxilla and septa emerging from the lateral and inferior walls of the maxillary sinus (arrows).

\section{Discussion}

The maxillary sinus is the first paranasal sinus to form. Pneumatization of the sinus begins after birth, continues through early adulthood, and is fully completed at the age of eighteen. There are two phases of rapid maxillary sinus growth; the first occurs during the first three years after birth and the second between the ages of seven and twelve [1]. At the end of pneumatization, the maxillary sinus has a pyramidal shape with the base toward the lateral nasal wall and the apex directed toward the zygomatic bone [1] [3]. Anatomical variations, such as pneumatization, can change the volume and shape of the sinus.

The present report revealed a case of maxillary sinus extension in association with a septum. These two anatomical variations of the maxillary sinus are common and are routinely observed in radiographs in dental practice. However, radiograph images have some limitations. They provide only two-dimensional X-ray images of three-dimensional structures. In this case, СВСТ helped to diagnose the cause of maxillary sinus radiolucency observed in the periapical image. CBCT of the axial, coronal and sagittal planes provided detailed images of 
maxillary sinus alveolar extension toward the palatal cortical bone in addition to an antral septum.

CBCT has been increasingly utilized to assess anatomical variations, as the modality allows for accurate identification and high anatomical detail. Lana et al. (2011) [5] evaluated anatomical variations and lesions of the maxillary sinus in 500 CBCT exams taken as part of dental implant planning. Maxillary sinus alveolar pneumatization was observed in 416 cases (83.2\%) and was the most common anatomic variation detected. Earwaker (1993) [10] evaluated 800 computed tomography scans to determine the prevalence of paranasal sinus anatomic variants. The author found alveolar recesses in 150 cases. These recesses were more common in edentulous patients, and the recesses in dentate patients had an intimate relationship with premolar and molar roots.

Alveolar extension associated with the septum was also present. The septa are thin walls of cortical bone projecting from inferior and lateral walls of the maxillary sinus. Septa vary in number, thickness and length [7]. The presence of maxillary sinus septa increases the risk of sinus membrane perforation during surgical sinus elevation or sinus lift for implant placement [11] and may result in the development of acute or chronic sinusitis [5]. Underwood (1910) [8] described the following three septa locations: the anterior region between the roots of second premolar and first molar; a middle region between the roots of the first and second molars; and a posterior region in the area of the third molar. These three areas of septa position correspond to three periods of tooth eruption: the anterior location corresponds to the eruption of milk molars (between 8 months and 2 years); the large middle area corresponds to the eruption of the first and second permanent molars (between 5 to 12 years); and the posterior location corresponds to the eruption of the third molars (between 16 to 30 years) [9]. According to the Underwood [8] classification, the patient in the present study had a septum in the anterior position. The projection of this anatomical variation in a single plane was responsible for the well-defined radiolucency observed in periapical radiography.

A number of studies have revealed the prevalence of septa. Kim et al. (2006) [12] evaluated computed tomography images of 100 patients and observed a prevalence of one or more septa per sinus in 53 of 200 sinuses (26.5\%). Similar results were presented by Lee et al. (2010) [13], who reported that sinus septa were present in 58 of the 236 maxillary sinuses evaluated (24.6\%). Shibli et al. (2007) [14] reported a prevalence of $21.58 \%$. Lana et al. (2011) [5] detected antral septa in $44.4 \%$ of scans, which was almost half of the exams. Most of the septa were unilateral (121 of 222 cases).

No relationship has been found between the prevalence of septa and the age and sex of patients. However, some studies have reported higher rates of septa in edentulous patients when compared to partially edentulous patients [9]. Faramarzie et al. (2009) [15] reported at least one septum in $35.52 \%$ of edentulous patients and $21.42 \%$ of dentate patients. Lee et al. (2010) [13] reported maxillary sinus septa in $27.7 \%$ of edentulous patients and $19.3 \%$ of dentate patients. The higher prevalence of septa in the edentulous ridge can be explained bythe resorption of the maxillary alveolar ridge after tooth loss, which causes pneumatization of the maxillary sinus and leads to the formation of secondary septa [13] [15]. This classification of the septa into primary and secondary was proposed by Krennmair et al. (1999) [16]. Primary septa result from the development of the maxilla, whereas secondary septa are a consequence of the pneumatization of the inferior sinus wall that occurs after tooth loss [13].

\section{Conclusion}

In conclusion, detailed knowledge of the anatomy of the maxillary sinus and associated anatomical variations is very important because it can influence planning for dental procedures. Cone-beam computed tomography provides three-dimensional images without overlapping structures that have become an important diagnostic tool in dentistry. In this case, CBCT was used to identify maxillary sinus alveolar extension with antral septum, revealing the artifact observed in periapical radiograph. However, interpretation of CBCT images must be performed by those familiar with the relevant anatomy and an understanding of the spatial relationships in the image volume.

\section{Acknowledgements}

This work was supported by the Conselho Nacional de Pesquisa (CNPq), Brazil.

\section{References}

[1] Lawson, W., Patel, Z.M. and Lin, F.Y. (2008) The Development and Pathologic Processes That Influence Maxillary 
Sinus Pneumatization. Anatomical Record, 291, 1554-1563. http://dx.doi.org/10.1002/ar.20774

[2] Dwivedi, A.N.D. and Singh, K.K. (2010) CT of the Paranasal Sinuses: Normal Anatomy, Variants and Pathology. Journal of Optoelectronics and Biomedical Materials, 2, 281-289.

[3] Ogle, O.E., Weinstock, R.J. and Friedman, E. (2012) Surgical Anatomy of the Nasal Cavity and Paranasal Sinuses. Oral Maxillofacial Surgery Clinics of North America, 24, 155-166. http://dx.doi.org/10.1016/j.coms.2012.01.011

[4] Araújo Neto, S.A., Martins, P.S.L., Souza, A.S., Baracat, E.C.E. and Nanni, L. (2006) O papel das variantes anatômicas do complexo ostiomeatal na rinossinusite crônica. Radiologia Brasileira, 39, 227-232. http://dx.doi.org/10.1590/S0100-39842006000300014

[5] Lana, J.P., Carneiro, P.M.R., Machado, V.C., Souza, P.E.A., Manzi, F.R. and Horta, M.V.R. (2011) Anatomic Variations and Lesions of the Maxillary Sinus Detected in Cone Beam Computed Tomography for Dental Implants. Clinical Oral Implants Research, 23, 1398-1403. http://dx.doi.org/10.1111/j.1600-0501.2011.02321.x

[6] Miloglu, O., Yilmaz, A.B., Yildirim, E. and Akgul, H.M. (2011) Pneumatization of the Articular Eminence on Cone Beam Computed Tomography: Prevalence, Characteristics and a Review of the Literature. Dentomaxillofacial Radiology, 40, 110-114. http://dx.doi.org/10.1259/dmfr/75842018

[7] Miranda, C.M.N.R., Maranhã, C.P.M., Arraes, F.M.N.R.A., Padilha, I.G., Farias, L.P.G., Jatobá, M.S.A., et al. (2011) Anatomical Variations of Paranasal Sinuses at Multislice Computed Tomography: What to Look for. Radiologia Brasileira, 44, 256-262.

[8] Underwood, A.S. (1910) An Inquiry into the Anatomy and Pathology of the Maxillary Sinus. Journal of Anatomy and Physiology, 44, 354-369.

[9] Maestre-Ferrín, L., Galán-Gil, S., Carrillo-García, C. and Peñarrocha-Diago, M. (2011) Radiographic Findings in the Maxillary Sinus: Comparison of Panoramic Radiography with Computed Tomography. International Journal of Oral Maxillofacial Implants, 26, 341-346.

[10] Earwaker, J. (1993) Anatomic Variants in Sinonasal CT. Radiographics, 13, 381-415. http://dx.doi.org/10.1148/radiographics.13.2.8460226

[11] Orhan, K., Kusakci Seker, B., Aksoy, S., Bayindir, H., Berberoglu, A. and Seker, E. (2013) Cone Beam CT Evaluation of Maxillary Sinus Septa Prevalence, Height, Location and Morphology in Children and an Adult Population. Medical Principles and Practice, 22, 47-53. http://dx.doi.org/10.1159/000339849

[12] Kim, M.J., Jung, U.W., Kim, C.S., Kim, K.D., Choi, S.H., Kim, C.K. and Cho, K.S. (2006) Maxillary Sinus Septa: Prevalence, Height, Location, and Morphology. A Reformatted Computed Tomography Scan Analysis. Journal of Periodontology, 77, 903-908. http://dx.doi.org/10.1902/jop.2006.050247

[13] Lee, W.J., Lee, S.J. and Kim, H.S. (2010) Analysis of Location and Prevalence of Maxillary Sinus Septa. Journal of Periodontal Implant Science, 40, 56-60. http://dx.doi.org/10.5051/jpis.2010.40.2.56

[14] Shibli, J.A., Faver, M., Ferrari, D.S., Melo, L., Garcia, R.V., D’avila, S., et al. (2007) Prevalence of Maxillary Sinus Septa in 1024 Subjects with Edentulous Upper Jaws: A Retrospective Study. Journal of Oral Implantology, 33, 293296. http://dx.doi.org/10.1563/1548-1336(2007)33[293:POMSSI]2.0.CO;2

[15] Faramarzie, M., Babaloo, A.R. and Oskouei, S.G. (2009) Prevalence, Height, and Location of Antral Septa in Iranian Patients Undergoing Maxillary Sinus Lift. Journal of Periodontology Implant Dentistry, 1, 43-47.

[16] Krennmair, G., Ulm, C.W., Lugmayr, H. and Solar, P. (1999) The Incidence, Location and Height of Maxillary Sinus Septa in the Edentulous and Dentate Maxilla. Journal of Oral and Maxillofacial Surgery, 57, 667-671. http://dx.doi.org/10.1016/S0278-2391(99)90427-5 
Scientific Research Publishing (SCIRP) is one of the largest Open Access journal publishers. It is currently publishing more than 200 open access, online, peer-reviewed journals covering a wide range of academic disciplines. SCIRP serves the worldwide academic communities and contributes to the progress and application of science with its publication.

Other selected journals from SCIRP are listed as below. Submit your manuscript to us via either submit@scirp.org or Online Submission Portal.
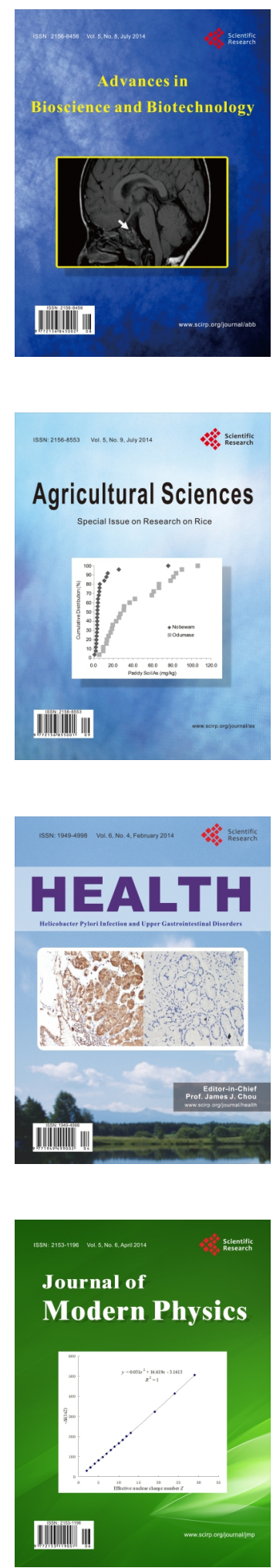
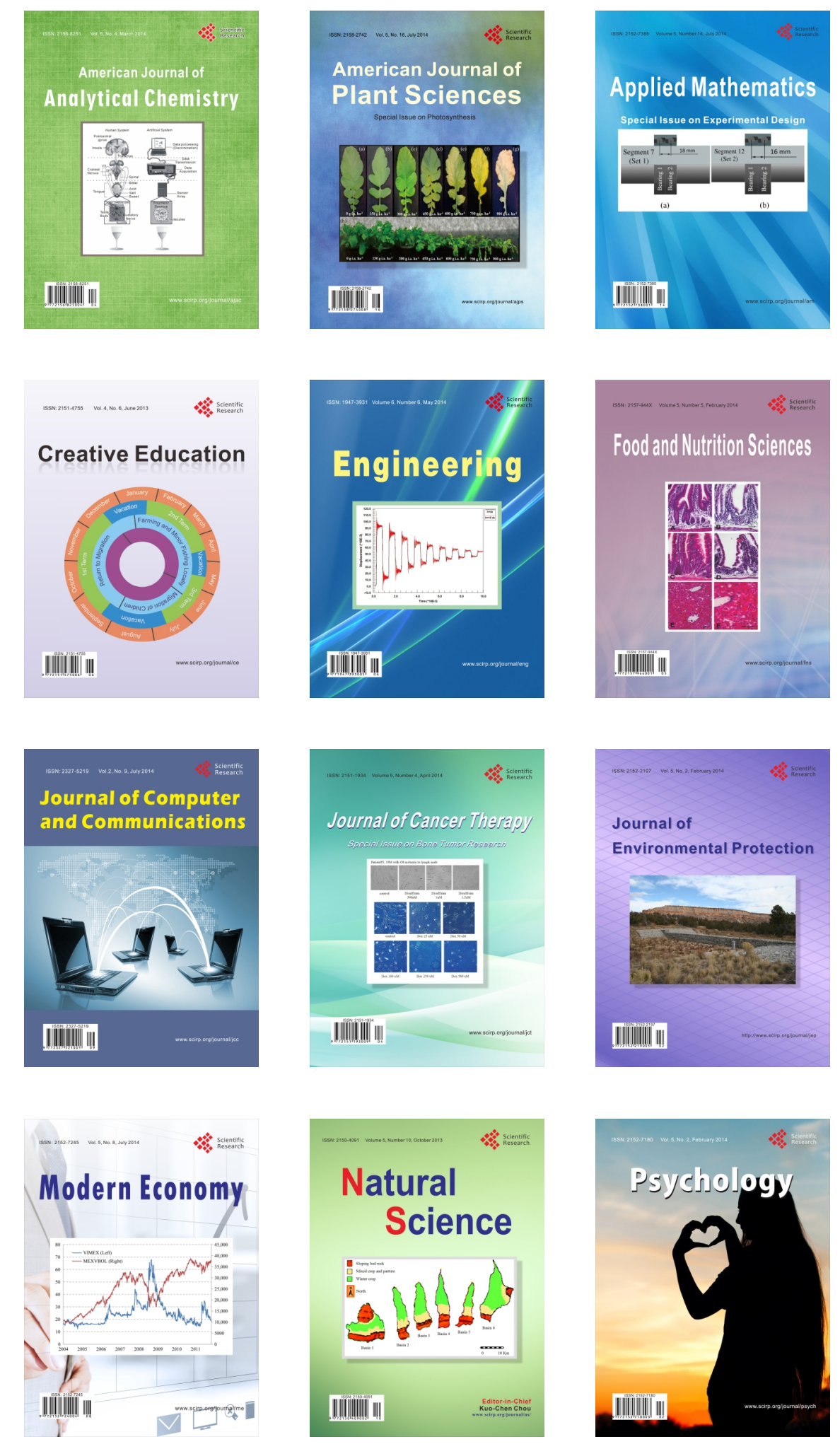